Elsevier required licence: (C) <2019>. This manuscript version is made available under the CC-BY-NC-ND 4.0 license http://creativecommons.org/ licenses/by-nc-nd/4.0/. The definitive publisher version is available online at [insert DOI] 


\title{
Food waste based biochars for ammonia nitrogen removal from
} aqueous solutions

\author{
Shan Xue $e^{\mathrm{a}, \mathrm{b}, 1}$, Xinbo Zhang ${ }^{\mathrm{a}, \mathrm{b}, 1}$, Huu Hao Ngo ${ }^{\mathrm{a}, \mathrm{c}, *}$, Wenshan Guo ${ }^{\mathrm{a}, \mathrm{c}}$, Haitao Wen ${ }^{\mathrm{a}, \mathrm{b}}$, \\ Chaocan Li ${ }^{\mathrm{a}, \mathrm{b}}$, Yongzhao Zhang ${ }^{\mathrm{a}, \mathrm{b}}$, Chanjuan $\mathrm{Ma}^{\mathrm{a}} \mathrm{b}$
}

${ }^{a}$ Joint Research Centre for Protective Infrastructure Technology and Environmental Green Bioprocess, Department of Environmental and Municipal Engineering, Tianjin Chengjian University, Tianjin 300384, China and School of Civil and Environmental Engineering, University of Technology Sydney, NSW 2007, Australia

${ }^{b}$ Tianjin Key Laboratory of Aquatic Science and Technology, Tianjin Chengjian University, Jinjing Road 26, Tianjin 300384, China

${ }^{c}$ Centre for Technology in Water and Wastewater, School of Civil and Environmental Engineering, University of Technology Sydney, Sydney, NSW 2007, Australia

${ }^{1}$ Equal contribution

*Correspondence author.Email address: ngohuuhao121@gmail.com 


\section{Abstract}

Biochar derived from waste has been increasingly considered as a potential green adsorbent due to its significant ability and affordable production costs. This study prepared and evaluated 7 types of food waste-based biochars (FWBBs) (including meat and bone, starchy staples, leafy stemmed vegetables, nut husks, fruit pericarp, bean dreg and tea leaves). The impacts of raw materials, pyrolysis temperatures $\left(300,400,500,600\right.$ and $\left.700{ }^{\circ} \mathrm{C}\right)$, and residence time ( $2 \mathrm{~h}$ and $4 \mathrm{~h}$ ) on the removal of ammonia nitrogen at different ammonia nitrogen concentrations $(5,10,20,50,100,150 \mathrm{mg} / \mathrm{L})$ were investigated. The batch equilibrium and kinetic experiments confirmed that a FWBB dosage of $3 \mathrm{~g} / \mathrm{L}$ at $25^{\circ} \mathrm{C}$ could remove up to $92.67 \%$ ammonia nitrogen. The Langmuir isotherm model had the best fit to equilibrium experimental data with a maximum adsorption capacity of $7.174 \mathrm{mg} / \mathrm{g}$ at $25^{\circ} \mathrm{C}$. The pseudo-second order kinetic model well describes the ammonia nitrogen adsorption. Keynote: Food waste based biochars, green adsorbent, ammonia nitrogen removal, aqueous solutions

\section{Introduction}

Food waste (FW) is a major component of municipal solid waste, and it mainly includes materials intended for human consumption that are subsequently discharged, lost, degraded or contaminated which contain a large amount of organic compounds (Girotto et al., 2015). With increasing amounts of food waste output in China, this has become a serious environmental problem. Recent data, for the annual output of food waste in China is about 400 million tons, accounting for about $60 \%$ of the total production of domestic waste, with the treatment rate being less than 5\%. Low treatment rates for abundant food waste have contributed to large 
volumes dumped in landfill causing bad odor, flies and vermin (Ahmed \& Gupta, 2010). Inappropriate dumping of food waste has also led to an increase in different gaseous emissions, landfill leachate precipitation, and other environmental problems which could contaminate surface water and groundwater. As a result, a 'green' measure is required to: firstly, provide a more sustainable solution when managing food waste; and secondly, alleviate the burden regarding these unsustainable rates and consumption of resources.

Economic development and improvements in people's living standards have increased significant amounts of wastewater which means that pollutants such as organic matter, nutrients, heavy metals, etc., end up in receiving water sources. Thus, nutrients in water will become overloaded and contribute to a brief frenzy of algal growth which in turn depletes dissolves oxygen in the water. This induces death in many aquatic animals, such as fish, shrimp and crab species. Water eutrophication has subsequently become a major environmental problem in China. For this reason it is imperative and urgent to develop methods that can remove nitrogen from wastewater.

Recently, biomass as one of the recycle materials owing to high carbon content has been used to produce fuel and energy, such as biogas, biooil and biochar (Samar Elkhalif, 2019). Biochar is produced by a series of pyrolysis processes where oxygen is absent at high temperature ranging from 300 to $700^{\circ} \mathrm{C}$. Furthermore, (Akdeniz, 2019) suggests biochar is a new type of adsorbent which is light in weight, with a porous and aromatic structure characterized by biological resistance and thermal stability (Godlewska et al., 2017; Spokas et al., 2011; Yu et al., 2018), which has a potential capacity for adsorption of nutrients, heavy 
metal and organic pollutants from municipal, agricultural and industrial waste waters (Jia et al., 2018; Komnitsas et al., 2015; Xu et al., 2019). Compared to activated carbon, biochar is a new type of adsorbent in which the preparation method is simple, especially the cheaper cost for preparation and ensuring energy efficiency. The raw materials for making biochar are typically agricultural waste, such as straw and rice husks. The use of agricultural waste as a raw material for the production of biochar saves energy consumption and furthermore reduces the wastage of biomass resources (Thines et al., 2017; Yavari et al., 2017).

The novelty of this study can be seen from discovering a new type of adsorbent made from food waste to removing ammonia nitrogen from aqueous solution and to meet the recycle demands of waste resources. Seven types of food waste were collected as raw materials to produce biochars for functioning as a sorbent for $\mathrm{NH}_{4}{ }^{+}-\mathrm{N}$ adsorption. This research also compares different preparation methods/conditions for optimization, and determines the best raw materials for biochars in terms of adsorption efficiency and economic cost-effectiveness.

\section{Materials and methods}

\subsection{Food waste sampling}

The food waste sample was collected from the first canteen of TCU (Tianjin Chengjian University). The sampling was done every day at lunch time for two weeks. The food waste samples were then classified into 7 types, these being: meat and bone (e.g., pork, beef, chicken, fish, shrimp and their bone), starchy staples (e.g., rive, noodles, steamed bun, bread and rice noodles), stems/leafy vegetables (e.g., cabbage, cauliflower, rape, broccoli), nut husks (e.g., chestnut shell, seed shell, peanut coat, walnut peel), fruit pericarp (e.g., orange 
peel, pineapple peel, sugarcane skin), bean dregs, and tea leaves.

\subsection{Food waste biochar preparation}

The food waste was dried outside for 48 hours and then put into an oven at $105^{\circ} \mathrm{C}$ for $24 \mathrm{hrs}$. Pyrolysis at the muffle furnace residence time lasted 2 and 4 hours, heating rate of $5^{\circ} \mathrm{C} / \mathrm{min}$, and setting the pyrolysis temperatures at $300,400,500,600$ and $700{ }^{\circ} \mathrm{C}$. The biochar was milled with a mortar and pestle, and put through a 100-mesh sieve. The biochars obtained from the 7 different feedstocks were designated as follows: fruit pericarp biochar (FPB), nut husk biochar (NHBC), bean dreg biochar (BDBC), tea leaves biochar (TLBC), stems/leafy vegetables biochar (SLVBC), starchy staples biochar (SSBC), and meat and bone biochar (MBBC).

\subsection{Food waste biochar characterization}

The carbon, hydrogen and nitrogen of raw materials and food waste biochar content samples were analyzed using an Elemental Analyzer (vario EI cube), whereas oxygen content was determined by mass balance: $\mathrm{O}=100-(\mathrm{C}+\mathrm{H}+\mathrm{N}+$ ash $)(\mathrm{Li}$ et al., 2018). Thermal Gravimetric Analyzer (TGA, STA449F3) served to investigate the thermal behavior of the raw materials of food waste biochar. The functional groups were detected employing the $\mathrm{KBr}$ tableting method with biochar samples subjected to Fourier-transform infrared spectroscopy (FTIR, Thermo Fisher Is10) and the spectra ranged from 4000 to $400 \mathrm{~cm}^{-1}$. The Scanning Electron Microscopy (SEM, JSM-7800F) provided morphological information on the surface of the sample and its composition. The surface area and pore size distribution were determined utilizing the Brunauer-Emmett-Teller (BET, Micromeritics TriStar II 3020) method. This helped to determine the nitrogen $\left(\mathrm{N}_{2}\right)$ adsorption/desorption at $77 \mathrm{~K}$ using a surface and pore size distribution. The $\mathrm{pH}$ levels of biochar samples were measured using a 
$\mathrm{pH}$ meter, biochar and distilled water with a mixing ratio of 1:20 shaken for 2 hours at a speed of $150 \mathrm{rpm}$. The biochar surface potential was detected by ZETA Analyzer.1 $\mathrm{g}$ of biochar and $20 \mathrm{~mL}$ deionized water were mixed in a $50 \mathrm{~mL}$ centrifugal tube. The $\mathrm{pH}$ values of mixture was adjusted between 2 and 12 using $0.1 \mathrm{~mol} / \mathrm{L} \mathrm{HCl}$ and $0.1 \mathrm{~mol} / \mathrm{L} \mathrm{NaOH}$. It was then shaken at $25{ }^{\circ} \mathrm{C}$ for 2 hours. The zeta potential of the biochars were measured.

\subsection{Batch adsorption experiments}

\subsubsection{Adsorption kinetics}

$0.1 \mathrm{~g}$ biochar was weighted in the centrifugal tube, and the $\mathrm{NH}_{4} \mathrm{Cl}$ solution $10 \mathrm{ml}$ with ammonia nitrogen concentrations were 5, 10, 20, 50, 100 and $150 \mathrm{mg} / \mathrm{L}$, respectively. These were then added to each centrifugal tube. The biochar mixtures were put in an incubator shaker setting temperature at $25^{\circ} \mathrm{C}$, shook at a speed of $150 \mathrm{rpm}$ for $24 \mathrm{hrs}$ and then put through a $0.45 \mu \mathrm{m}$ filter membrane. Finally, the concentration of the ammonia nitrogen in filtered liquor was measured using the colorimetric method. The experiments were carried out in triplicate, and the collected data was averaged.

Calculation of ammonia nitrogen adsorption by biochar in equilibrium meant using equation (1) $\mathrm{q}_{\mathrm{e}}\left(\mathrm{mg} \cdot \mathrm{g}^{-1}\right)$

$\mathrm{q}_{\mathrm{e}}=(\mathrm{Co}-\mathrm{Ce}) / \mathrm{M} \times \mathrm{V}$

where; $\mathrm{C}_{\mathrm{o}}$ and $\mathrm{C}_{\mathrm{e}}\left(\mathrm{mg} \cdot \mathrm{L}^{-1}\right)$ were the initial and equilibrium $\mathrm{NH}_{4}{ }^{+}-\mathrm{N}$ concentration in solution, respectively; qe $\left(\mathrm{mg} \cdot \mathrm{g}^{-1}\right)$ was the adsorbed amount of $\mathrm{NH}_{4}{ }^{+}-\mathrm{N}$ at equilibrium, $\mathrm{V}(\mathrm{L})$ was the volume of solution used, and $\mathrm{M}(\mathrm{g})$ the mass of biochar.

\subsubsection{Adsorption isotherms}


$0.1 \mathrm{~g}$ biochar was weighted in the centrifugal tube, and the $\mathrm{NH}_{4} \mathrm{Cl}$ solution $10 \mathrm{ml}$ and an ammonia nitrogen concentration of $150 \mathrm{mg} / \mathrm{L}$ was added. The biochar mixtures were put in an incubator shaker setting temperature at $25^{\circ} \mathrm{C}$, shook at a speed of $150 \mathrm{rpm}$ for $5,15,30,60$, $120,240,480,960,1440$, and $2880 \mathrm{~min}$ and then put through a $0.45 \mu \mathrm{m}$ filter membrane. Here the HJ535-2009 Na reagent spectrophotometry helped to determine the concentration of ammonia nitrogen in the filter. The adsorption amount of biochar to ammonia nitrogen was calculated using equation $(2) \mathrm{q}_{\mathrm{t}}(\mathrm{mg} / \mathrm{g})$

$\mathrm{q}_{\mathrm{t}}=\left(\mathrm{C}_{\mathrm{o}}-\mathrm{C}_{\mathrm{t}}\right) / \mathrm{M} \times \mathrm{V}$

where ; $\mathrm{C}_{\mathrm{o}}$ and $\mathrm{C}_{\mathrm{t}}\left(\mathrm{mg} \cdot \mathrm{L}^{-1}\right)$ are the initial and time $\mathrm{NH}_{4}{ }^{+}-\mathrm{N}$ concentration in solution, respectively; $\mathrm{q}_{\mathrm{t}}\left(\mathrm{mg} \cdot \mathrm{g}^{-1}\right)$ was the adsorbed amount of $\mathrm{NH}_{4}{ }^{+}-\mathrm{N}$ at time $\mathrm{t}, \mathrm{V}(\mathrm{L})$ was the volume of solution used, and $\mathrm{M}(\mathrm{g})$ the mass of biochar.

\subsubsection{Adsorption thermodynamics}

To investigate the thermodynamics study of ammonia nitrogen adsorption onto the biochar, $0.1 \mathrm{~g}$ biochar was weighted in the centrifugal tube, and $10 \mathrm{ml} \mathrm{NH}_{4} \mathrm{Cl}$ solution with initial ammonia nitrogen concentration of $150 \mathrm{mg} / \mathrm{L}$ was added and shook at a speed of $150 \mathrm{rpm}$ at a temperature of $15,25,35^{\circ} \mathrm{C}$ respectively for $24 \mathrm{~h}$ to reach the equilibration. From four parameters of the equilibrium data: Gibb's free energy change $\left(\Delta \mathrm{G}^{\circ}\right)$, enthalpy change $\left(\Delta \mathrm{H}^{\circ}\right)$, entropy change $\left(\Delta \mathrm{S}^{\circ}\right)$ and thermodynamics constant $(\mathrm{K} \mathrm{c})$ were calculated. The thermodynamic equilibrium constant $\mathrm{K}$, is given by the equation:

$\mathrm{K} \mathrm{c}=\left(\mathrm{C}_{\mathrm{o}}-\mathrm{C}_{\mathrm{e}}\right) / \mathrm{C}_{\mathrm{e}}$

where: $\mathrm{C}_{\mathrm{o}}$ and $\mathrm{C}_{\mathrm{e}}\left(\mathrm{mg} \cdot \mathrm{L}^{-1}\right)$ are the initial and equilibrium $\mathrm{NH}_{4}{ }^{+}-\mathrm{N}$ concentration in solution, respectively; 
The $\Delta \mathrm{G}^{\circ}$ was related to the $\mathrm{K} \mathrm{c}$ by the equation:

$\Delta \mathrm{G}^{\mathrm{o}}=-\mathrm{RT}$ In $\mathrm{K}$

where; $\mathrm{T}$ is the temperature $(\mathrm{K}), \mathrm{R}$ is the universal gas constant $\left(8.314 \mathrm{~J} \mathrm{~mol}^{-1} \mathrm{~K}^{-1}\right)$

According to van't Hoff's thermodynamics equation, the values of $\Delta \mathrm{S}^{\circ}$ and $\Delta \mathrm{H}^{\circ}$ were respectively obtained from the intercept and slope of the plot between $\operatorname{lnK}$ and 1/T (van't Hoffplot) by the equation:

$\Delta \mathrm{G}^{\mathrm{o}}=\Delta \mathrm{H}^{\mathrm{o}}-\mathrm{T} \Delta \mathrm{S}^{\mathrm{o}}$

$\ln \mathrm{K}=-\Delta \mathrm{H}^{\mathrm{o}} / \mathrm{R}(1 / \mathrm{T})+\Delta \mathrm{S} / \mathrm{R}$

\section{5. Effect of pH}

The amount of $0.1 \mathrm{~g}$ biochar was weighted in the centrifugal tube, and a $\mathrm{NH}_{4} \mathrm{Cl}$ solution $10 \mathrm{ml}$ with ammonia nitrogen concentration of $150 \mathrm{mg} / \mathrm{L}$ was added. The initial $\mathrm{pH}$ values were adjusted to 3,5,7,9 and 11 with $\mathrm{HCl}$, and $\mathrm{NaOH}$. The biochar mixtures were put in an incubator shaker setting temperature at $25^{\circ} \mathrm{C}$, shook at a speed of $150 \mathrm{rpm}$ for $24 \mathrm{hrs}$ and then put through a $0.45 \mu \mathrm{m}$ filter membrane. Finally, the concentration of ammonia nitrogen in the filtered liquor was measured. The removal rate of ammonia nitrogen was calculated by formula (7), and the effect of initial $\mathrm{pH}$ value of solution on adsorption was investigated.

Subsequently the optimum $\mathrm{pH}$ value was determined as follows:

$\mathrm{W}=\left(\mathrm{C}_{\mathrm{o}}-\mathrm{C}_{\mathrm{e}}\right) / \mathrm{C}_{\mathrm{o}} \times 100 \%$

where; $\mathrm{C}_{\mathrm{o}}$ and $\mathrm{C}_{\mathrm{e}}\left(\mathrm{mg} \cdot \mathrm{L}^{-1}\right)$ are the initial and equilibrium $\mathrm{NH}_{4}{ }^{+}-\mathrm{N}$ concentration in solution, respectively; and $\mathrm{w}$ is the removal rate of ammonia nitrogen.

\section{6 Effect of dosage of biochar}

The following amounts $-0.1 \mathrm{~g}, 0.2 \mathrm{~g}, 0.3 \mathrm{~g}, 0.5 \mathrm{~g}, 0.8 \mathrm{~g}, 1.0 \mathrm{~g}, 2.0,3.0$ and 4.0 biochar - were weighted in the centrifugal tube, respectively, and the $\mathrm{NH}_{4} \mathrm{Cl}$ solution at $10 \mathrm{ml}$ with an 
ammonia nitrogen concentration of $150 \mathrm{mg} / \mathrm{L}$ was added. The biochar mixtures were put in an incubator shaker setting temperature at $25^{\circ} \mathrm{C}$, shook at a speed of $150 \mathrm{rpm}$ for $24 \mathrm{hrs}$ and then put through a $0.45 \mu \mathrm{m}$ filter membrane. Finally, the concentration of the ammonia nitrogen in the filtered liquor was measured. Using equation (1) helped to calculate the adsorption amount of ammonia nitrogen in equilibrium, the efficiency in removing ammonia nitrogen was calculated by equation (7), the effect of the biochar dosage on the adsorption was investigated, and the optimum biochar dosage was determined.

\subsection{Effect of temperature}

The procedure was as same as Section 2.4.3. The solution was then filtered through the $0.45 \mu \mathrm{m}$ filter membrane and its ammonia nitrogen was analyzed. The ammonia nitrogen removal efficiency $\mathrm{W}$ was calculated by formula (2), the effect of temperature on adsorption was investigated, and the optimum adsorption temperature was determined.

\section{Results and discussion}

\subsection{Characterization study}

\subsubsection{Raw material properties}

In order to analyze characteristics of the best raw materials, the chemical compositions of these materials are listed in Table 1. The $\mathrm{pH}$ of raw materials ranged from 4.76 to 6.37 , which was consistent with the findings of a previous study (Vassilev et al., 2010). It was found that the raw biomass remained weakly acidic or neutral. Based on the elemental analysis, it can be seen that all of these raw materials, except for meat and bone, were rich in carbon content ranging from $42 \%$ to $49 \%$. For meat and bone, carbon content and fixed carbon are less than that of the other raw materials. Furthermore, higher carbon content is more suitable for the 
preparation of biochar. Alternatively, the ash of meat and bone is also the largest and it contains a higher mineral composition, which is not suitable for the preparation of biochar.

On the other hand, the raw materials $\mathrm{C} \% \geq 45$ biological carbon such as fruit pericarp, bean dreg, tea leaves, and nut husks have an adsorption capacity that is better than the others. Studied shows that fixed carbon is an important agent for the preparation of biochar (Dhyani \& Bhaskar, 2017).

\section{Table 1}

Table 2 indicates that the pyrolysis condition and especially maximum pyrolysis temperature during biochar preparation do exert a large impact on the biochars' physical and chemical characteristics (Sun et al., 2014; Tang et al., 2019). Generally, with pyrolysis temperature increasing from 300 to $700{ }^{\circ} \mathrm{C}$, carbon content increased from $55 \%$ to $89 \%$; meanwhile oxygen and hydrogen content declined from $27 \%$ to $3 \%$, and $6 \%$ to $1 \%$, respectively. The exception in this case was MBBC, where carbon content decreased from $37 \%$ to $24 \%$. For FPBC, NHBC, TFBC the carbon content increased while the oxygen contents decreased as temperature rose; however, the $\mathrm{BDBC}, \mathrm{SLVBC}, \mathrm{SSBC}$ reached their maximum carbon and oxygen contents at $500^{\circ} \mathrm{C}$ and then remained stable.

\section{Table 2}

As shown in Figure 1, the Van Krevelen diagram, devised by Dirk van Krevelen in 1950 (Krevelen, 1950), can serve to show atomic ratios that evolved in the biochar produced at different pyrolysis temperatures. These served to describe the progression of the carbonization process. The atomic ratios $\mathrm{H} / \mathrm{C}, \mathrm{O} / \mathrm{C}$ and $(\mathrm{N}+\mathrm{O}) / \mathrm{C}$ have been used to estimate the aromaticity, hydrophilicity and polarity of biochars. When the temperature increased from $300^{\circ} \mathrm{C}$ to $700^{\circ} \mathrm{C}$, the $\mathrm{H} / \mathrm{C}$ and $(\mathrm{N}+\mathrm{O}) / \mathrm{C}$ ratios of the biochar decreased, which indicated there was lower 
aromaticity and higher polarity for the biochars produced at $300{ }^{\circ} \mathrm{C}$ compared to at $700{ }^{\circ} \mathrm{C}$, respectively. This change was due to the surface polar functional groups being removed and the formation of aromatic structures for biochar being produced at a higher pyrolysis temperature (Jung et al., 2016; Xu et al., 2019). From Figure 1, the biochar pyrolysis at $300^{\circ} \mathrm{C}$, BDBC with the larger $\mathrm{H} / \mathrm{C}$ ratio would be expected to have less aromaticity; $\mathrm{NHBC}$ and TFBC with a larger $\mathrm{O} / \mathrm{C}$ ratio would be expected to have more polarity. Thus, the temperature of biochar's preparation of this study was lower than that of other biochars (Kizito et al., 2015; Li et al., 2018; Takaya et al.,2016).

\section{Figure 1}

\subsubsection{Biochar characteristics}

Table 3 summarizes the characteristics of the food waste-based biochar. The pyrolysis temperature had an effect on the biochars' physico-chemical properties such as $\mathrm{pH}$, surface charge, elemental composition, ash content, volatile matter content, fixed carbon content, surface area, and thermal stability (Chen et al., 2014; Shaaban et al., 2014). It was shown that the $\mathrm{pH}$ values of biochar after pyrolysis were higher than that of the raw materials. The mainly acidic functional groups were decomposed during pyrolysis at higher temperature, such as hydroxyl and carboxyl, which led to an increase in $\mathrm{pH}$ value. Except for the MBBC, the surface area and total pore volume of FPBC, NHBC and TLBC were higher than the others, showing the superior adsorption capacity for $\mathrm{NH}_{4}{ }^{+}$. The carbon contents of FPBC, NHBC and TLBC were $63 \%, 75 \%$ and $72 \%$ respectively. This was mainly attributed to the raw materials containing more cellulose and lignose, which were converted into higher fixed carbon during pyrolysis. The ash contents of MBBC and SLVBC were 53\% and 28\%, respectively, which demonstrated that the two raw materials' content comprised larger 
concentrations of mineral elements (Huda Abdulrazzaq, 2014).

\section{Table 3}

The increase in residence time allowed sufficient time for the constituents of the biomass to undergo repolymerization reaction. Briefer residence time resulted in the incomplete repolymerization of the biomass constituents. The residence time greatly impacts the time taken for the carbonization process to finish due to the specific features of the biochars' surface area and pores volumes (Park et al., 2008; Yavari et al., 2017). However, for biochar pyrolysis using a temperature $>500^{\circ} \mathrm{C}$, the pore volume was higher than at lower temperature. The increased surface area of the biochar at the higher pyrolysis temperature existed because volatile substances released from biomass left the channel structures. These structures enhanced the biochar surface area and the pore structure (Kim et al., 2013; Li et al., 2013). However, referring to the $\mathrm{NHBC}$ the shape of its pore structure at $700^{\circ} \mathrm{C}$, it showed less porous structure and was more amorphous. This may have occurred because a temperature that was too high destroyed the raw material's original carbon structure. As a result, for raw materials such as tea leaves and fruit pericarp, a higher temperature could contribute to forming larger pore structures. However, for nut husks a temperature that is too high in turn affects the raw material's original structure, subsequently leading to structural fracture.

The 7 types of food waste-based biochar created at 2 hours and 4 hours were compared, and it is suggested that biochar derived from lignocellulosic (for example TLBC, NHBC and FPBC) sources showed a relatively higher surface area and pore volume. This finding corresponded with the better adsorption capacity for ammonia nitrogen. In previous studies, proximate analysis served to examine the chemical constituent components. The materials, specifically FPBC, NHBC and TLBC produced a large amount of fixed carbon $(>60 \%)$ which was due to 
pyrolysis. The larger amount of fixed carbon was more suitable for preparing biochar (Leng et al., 2019). Corresponding with the Scanning Electron Microscopy (SEM) it emerged that FPBC, NHBC and TLBC had more stable and dense carbon structures at lower pyrolysis temperature. According to (Takaya et al., 2016) in their analysis, feedstocks containing more lignocellulosic content and less ash indicated higher Cation Exchange Capacity (CEC). In addition, adsorbents like zeolites were characterized by high cation exchange capacities (CECs) and high ammonium selective properties (Hedstro“m, 2001; M. Kithome, 1998).

\subsubsection{FTIR study}

The Fourier-transform infrared spectroscopy (FTIR) conducted on the biochar before and after adsorption of $\mathrm{NH}_{4}{ }^{+}-\mathrm{N}$ was studied. From the FTIR spectra in the supplementary attachment, the functional groups before adsorption were O-H hydrogen-bonded hydroxyl (3420-3460 cm-1), C-H stretching, aliphatic $\mathrm{CH}_{\mathrm{x}}\left(2918-3973 \mathrm{~cm}^{-1}\right), \mathrm{C}=\mathrm{C}$ stretching or aromatic rings (1589-1630 $\left.\mathrm{cm}^{-1}\right),-\mathrm{CH}_{2}\left(1384-1417 \mathrm{~cm}^{-1}\right),-\mathrm{OH}$ phenolic hydroxyl groups $\left(1048-1113 \mathrm{~cm}^{-1}\right)$ and phenols $\left(558-619 \mathrm{~cm}^{-1}\right)$, respectively. After the adsorption of $\mathrm{NH}_{4}^{+}-\mathrm{N}$ the samples were analyzed via the FTIR, and it demonstrated that the wave peaks were weaker than before. The wave peak values of the spectra, namely the O-H hydrogen-bonded hydroxyl and phenols shrunk more than before. As a result, the functional groups played an important role in the adsorption of $\mathrm{NH}_{4}{ }^{+}-\mathrm{N}$ (Marco Keiluweit 2010).

\subsection{Adsorption experiments}

\subsubsection{Adsorption capacity of 7 types of food waste-based biochars}

As shown in Figure 2, adsorption capacity of 7 types of food waste-based biochars at different concentrations, i.e. 5, 10, 20, 50, 100, $150 \mathrm{mg} / \mathrm{L}$ were investigated. Biochar was 
produced using a lower temperature $\left(300^{\circ} \mathrm{C}\right.$ or $\left.400^{\circ} \mathrm{C}\right)$ and the adsorption capacity was larger than when using higher temperature, while the residence time of 4 hours proved to be superior to 2 hours. As a result, the 7 types of biochar (BDBC300, FPBC300, NHBC400, MBBC400, SLVBC400, SSBC400 and TLBC400) with their residence time lasting 4 hours were used for further investigation.

\section{Figure 2}

\subsubsection{Adsorption kinetics study}

Biochars were prepared from 7 different types of food waste and the adsorption kinetics of $\mathrm{NH}_{4}{ }^{+}-\mathrm{N}$ are illustrated in Fig.3. With the initial concentration of $150 \mathrm{mg} / \mathrm{L}$, the adsorption capacities of FPBC, NHBC, BDBC, TLBC, SLVBC, SSBC and MBBC increased as time passed. From this curve, the adsorption process could be divided into three parts. At the original time (0-250 min), the adsorption capacities of FPBC, NHBC, BDBC, TLBC and SLVBC increased rapidly. Meanwhile the rate for adsorption fell slowly from 250 to 1500 min. Moreover, after 1500 min the adsorption capacities did not increase instantly until these finally reached equilibration. Nonetheless, the SSBC and MBBC had adsorption capacities that were worse than the other 5 types of biochar and these two reached equilibriums at 1000 min earlier than the others.

\section{Figure 3}

In terms of equilibration time, all 7 types of food waste biochar completed adsorption processes in a period lasting $1500 \mathrm{~min}$. Owing to the maximum of equilibration adsorption amount, $\mathrm{FPBC}(\mathrm{Qe}=3.0992 \mathrm{mg} / \mathrm{g})$ emerged as a very promising adsorbent for ammonia nitrogen. To describe the mechanism for biochar adsorption of $\mathrm{NH}_{4}{ }^{+}-\mathrm{N}$, two kinds of adsorption kinetics model, pseudo-first order and pseudo-second order, were introduced to fit 
the relative adsorption experiment data. The expressions of these two adsorption models are documented immediately below:

Pseudo-first order kinetic equation: $\log \left(\mathrm{Q}_{\mathrm{e}}-\mathrm{Q}_{\mathrm{t}}\right)=\log \mathrm{Q}_{\mathrm{e}}-\mathrm{K}_{1} \mathrm{t} / 2.303$,

Pseudo-second order kinetic equation: $\mathrm{t} / \mathrm{Q}_{\mathrm{t}}=1 / \mathrm{K}_{2} \mathrm{Q}_{\mathrm{e}}{ }^{2}+\mathrm{t} / \mathrm{Q}_{\mathrm{t}}$,

where $\mathrm{Q}_{\mathrm{t}}\left(\mathrm{mg} \cdot \mathrm{g}^{-1}\right)$ represents the amount of $\mathrm{NH}_{4}{ }^{+}-\mathrm{N}$ adsorbed at time $\mathrm{t}$; $\mathrm{Q}_{\mathrm{e}}\left(\mathrm{mg} \cdot \mathrm{g}^{-1}\right)$

represents the amount of $\mathrm{NH}_{4}{ }^{+}-\mathrm{N}$ and TP adsorbed at equilibrium; $\mathrm{K}_{1}\left(\mathrm{~min}^{-1}\right)$ and $\mathrm{K}_{2}(\mathrm{~g} \cdot \mathrm{mg}$

${ }^{-1} \cdot \min ^{-1}$ ) are the rate constants of pseudo-first order and pseudo-second order, which can be

calculated from the plot of $\log \left(\mathrm{Q}_{\mathrm{e}}-\mathrm{Q}_{\mathrm{t}}\right)$ versus $\mathrm{t}$ and $\mathrm{t} / \mathrm{Q}_{\mathrm{t}}$ versus $\mathrm{t}$, respectively.

Compared to the fitting parameters of the pseudo-first order, and pseudo-second order regarding the adsorption of $\mathrm{NH}_{4}{ }^{+}-\mathrm{N}$ as summarized in Table 4, it emerged that the correlation coefficient (all $\mathrm{R}^{2}<0.99$ ) of the pseudo-first order did not fit the experiment data. This suggests that the adsorption process of $\mathrm{NH}_{4}{ }^{+}-\mathrm{N}$ on biochar does not follow the pseudo-first order kinetics. Conversely, the pseudo-second order kinetic equation (Y.S. Ho, 1999) does fit better the adsorption process of $\mathrm{NH}_{4}{ }^{+}-\mathrm{N}$ on biochar because of relatively high $\mathrm{R}^{2}$ values $\left(\mathrm{R}^{2}>0.99\right)$. The adsorption amount derived from the pseudo-second order kinetic equation had a better fit to the experimental equilibrium adsorption amount. This finding indicates that the adsorption of $\mathrm{NH}_{4}{ }^{+}-\mathrm{N}$ using the 7 types of biochars follows the pseudo-second order kinetics equation. Consequently, the adsorption process including liquid membrane diffusion, surface adsorption, and intraparticle diffusion, can be described as comprehensively reflecting the actual adsorption kinetics mechanism (Yan-Hong Jiang, 2019).

\section{Table 4}

\subsubsection{Adsorption isotherm study}

The different initial ammonia nitrogen concentrations of 5, 10, 20, 50, 100, $150 \mathrm{mg} / \mathrm{L}$ 
were studied utilizing the adsorption isotherm. By employing two kinds of adsorption isotherm models, the experimental data described the equilibrium adsorption processes of this study's 7 kinds of food waste biochar. The equations are as follows:

Langmuir equations $\mathrm{Q}_{\mathrm{e}}=\mathrm{C}_{\mathrm{e}} \mathrm{Q}_{\max } /\left(\mathrm{K}_{\mathrm{L}}+\mathrm{C}_{\mathrm{e}}\right)$

Freundlich equations $\mathrm{Q}_{\mathrm{e}}=\mathrm{K}_{\mathrm{F}} \mathrm{C}_{\mathrm{e}}{ }^{1 / \mathrm{n}}$

where $\mathrm{Q}_{\mathrm{e}}\left(\mathrm{mg} \cdot \mathrm{g}^{-1}\right)$ and $\mathrm{C}_{\mathrm{e}}\left(\mathrm{mg} \cdot \mathrm{L}^{-1}\right)$ are the amounts of adsorbed ammonia nitrogen and the ammonia nitrogen concentrations in the aqueous solution at equilibrium, respectively; $\mathrm{Q}$ max $\left(\mathrm{mg} \cdot \mathrm{g}^{-1}\right)$ is the maximum absorption capacity reached equilibrium; $\mathrm{K}_{\mathrm{L}}$ is the Langmuir constant; and $\mathrm{K}_{\mathrm{F}}$ represents the Freundlich adsorption equilibrium constant.

The fitting adsorption capacities documented in Table 5 and Figure 4 were compared with data from the 7 types of food-based biochar at 6 different initial concentrations. The results were that the correlation coefficients of each biochar fitting to $\mathrm{NH}_{4}{ }^{+}-\mathrm{N}$ in the Langmuir equation $\left(\mathrm{R}^{2}>0.90\right)$ were higher than the Freundlich equation. Consequently, the Langmuir equation is better to describe the adsorption process of $\mathrm{NH}_{4}{ }^{+}-\mathrm{N}$. The biochar adsorption process which belonged to the monolayer surface chemical adsorption, indicated that following the adsorption process adsorbate was distributed on the biochar pore structure's surface (Hale et al., 2013; Reguyal \& Sarmah, 2018). From the maximum of absorption capacity $\mathrm{Q}_{\max }$, the adsorption order was as follows:

TLBC $>$ SLVBC $>$ NHBC $>$ SSBC $>$ FPBC $>$ BDBC $>$ MBBC. The maximum and minimum of $\mathrm{Q}_{\max }$ were TLBC (7.174 mg/g) and MBBC (2.1745 mg/g), respectively. Furthermore, the BET surface area values and total pore volume of MBBC were $8.8128 \pm 0.0684$ and 8.308 , respectively. Based on these figures, the mechanisms of $\mathrm{NH}_{4}{ }^{+}$adsorption by $\mathrm{MBBC}$ were 
different from the other 6 type of biochars. The interrelationships between MBBC absorption capacity for $\mathrm{NH}_{4}{ }^{+}-\mathrm{N}$ and the specific surface area values, total pore volume were weak, respectively (Yan-Hong Jiang, 2019). However, for lignocellulosic biomass, such as fruit pericarp, tea leaves and nut husks, the specific surface area values and total pore volume were the two predominant factors affecting $\mathrm{NH}_{4}{ }^{+}$adsorption with biochar (Mukherjee et al., 2011).

\section{Table 5}

\section{Figure 4}

\subsection{Effect of biochar dosage on $\mathrm{NH}_{4}{ }^{+}-\mathrm{N}$ adsorption}

Figure 5(a) depicts the changes in $\mathrm{NH}_{4}{ }^{+}-\mathrm{N}$ removal efficiency when the biochar dosage increased from $0.1 \mathrm{~g}$ to $4.0 \mathrm{~g}$. When the mass of biochar was less than 3.0, the removal efficiency improved when the dosage was elevated. However, when the dosage was larger than 3.0 the removal efficiency did not increase until stability occurred. This phenomenon explains the fact that the adsorption activated site (Yang et al., 2018) is shielded (Yang et al., 2018). When mass $<3.0$, the number of_surface activated sites increased with the biochar mass increases in solution, which led to more $\mathrm{NH}_{4}{ }^{+}-\mathrm{N}$ being adsorbed. However, when the dosage of biochar $>3.0$, with the overloaded biochar in solution, the overlap of biochar dsorption layers contributed to the biochar surface available activated sites being shielded. Meanwhile the biochar in removing $\mathrm{NH}_{4}{ }^{+}-\mathrm{N}$ efficiency remained stable (Luo et al., 2019; Yin et al., 2018).

\section{Figure 5}

\subsection{Effect of $\mathrm{pH}$ on $\mathrm{NH}_{4}{ }^{+}-\mathrm{N}$ adsorption}

Figure 5(b) shows the effect of $\mathrm{pH}$ on $\mathrm{NH}_{4}{ }^{+}-\mathrm{N}$ adsorption capacity. For $\mathrm{pH}<4$ the amount 
adsorbed was lower but when $\mathrm{pH}$ increased from 4 to 7 , both FPBC and NHBC adsorption capacity increased until the maximum values were achieved, these being $3.72 \mathrm{mg} / \mathrm{g}$ and 2.62 $\mathrm{mg} / \mathrm{g}$, respectively. This is mainly because at lower $\mathrm{pH}$ levels, the aqueous solution has acidity which in turn contributes to functional groups on the biochar surface, which imparts a partial positive charge able to repel the polar attraction of $\mathrm{NH}_{4}{ }^{+}$ions (Mizuta et al., 2004; Yunnen et al., 2015). However, at a level of $\mathrm{pH}>8$ the $\mathrm{NH}_{4}{ }^{+}-\mathrm{N}$ is converted into $\mathrm{NH}_{3}$ but is not be able to connect with the biochar (Huang et al., 2010). This could explain why adsorption capacity declined.

\subsection{Effect of temperature on $\mathrm{NH}_{4}{ }^{+}-\mathrm{N}$ adsorption}

Figure 6 (a) indicates that $\mathrm{NH}_{4}{ }^{+}-\mathrm{N}$ adsorption capacity increased with temperature.

Temperature increased from $288.15 \mathrm{~K}$ to $308.15 \mathrm{~K}$, the adsorption capacity increased with increasing temperature and reach higher at $308.15 \mathrm{~K}$ with $4.969 \mathrm{mg} / \mathrm{g}$ for FPBC 300-4 and $4.579 \mathrm{mg} / \mathrm{g}$ for NHBC. From Figure 6(a), the effect of temperature on NHBC 400-2 and NHBC 400-4 depicted not much differences. Thermodynamic study suggests that NH4+-N adsorption is endothermic reaction as a result higher temperature will help to achieve maximum adsorption.

\section{Figure 6}

\subsection{Adsorption thermodynamics}

The values of $\mathrm{K} \mathrm{c}, \Delta \mathrm{G}^{\circ}, \Delta \mathrm{H}^{\circ}$ and $\Delta \mathrm{S}^{\circ}$ at different adsorption temperatures with initial $\mathrm{NH}_{4}{ }^{+}$ -N concentration of $150 \mathrm{mg} / \mathrm{L}$ are shown in Table 6 and Fig. $6(\mathrm{~b}) . \Delta \mathrm{H}^{\circ}$ for FPBC 300-4 and NHBC 400-4 were 12.384 and 17.833 from $\mathrm{NH}_{4} \mathrm{Cl}$ solution respectively. From Table 6 , the value $\mathrm{K} \mathrm{c}$ was increased with temperature. The $\Delta \mathrm{H}^{\circ}>0$ indicated that $\mathrm{NH}_{4}{ }^{+}$adsorption was endothermic. At the same time, the positive $\Delta \mathrm{S}^{\circ}$ values indicated that 
the disorder and randomness of liquid-solid phase interaction at the biochar surface increased after adsorption (Kizito et al., 2015).Meanwhile, with the positive $\Delta \mathrm{H}^{\circ}, \Delta \mathrm{S}^{\circ}$ and $\Delta \mathrm{G}^{\circ}$ demonstrated the adsorption process was not spontaneous at lower temperature.

\section{Table 6}

\section{Conclusions}

The influence of the type of raw material, biochar production temperature, and residence time on $\mathrm{NH}_{4}{ }^{+}-\mathrm{N}$ adsorption were all significant in this study. The biochar made from food waste can function as a valuable adsorbent of $\mathrm{NH}_{4}{ }^{+}-\mathrm{N}$. Raw materials like fruit pericarp and nut husk indicated better effective adsorption, but starchy staples, meat and bone was the least effective. Effect of type of raw material, the temperature used for biochar production and residence time on $\mathrm{NH}_{4}{ }^{+}-\mathrm{N}$ adsorption also proved to be significant. Finally, the results showed that food waste-based biochar has great potential for removing ammonia nitrogen in aqueous solution.

\section{Acknowledgements}

The work was supported by Tianjin Municipal Science and Technology Bureau (No.

18PTZWHZ00140).The authors are grateful for the support of Tianjin Chengjian University, School of Environmental and Municipal Engineering and University of Technology, Sydney, Centre for Technology in Water and Wastewater, as well as School of Civil and Environmental Engineering.

\section{Supplementary information}

Supplementary materials associated with this article can be found in the online version. 


\section{References}

[1]Ahmed, I.I., Gupta, A.K. 2010. Pyrolysis and gasification of food waste Syngas characteristics and char gasification kinetics. Appl. Energy, 87(1), 101-108.

[2]Akdeniz, N. 2019. A systematic review of biochar use in animal waste composting. Waste Manage. 88, 291-300.

[3]Chen, T., Zhang, Y., Wang, H., Lu, W., Zhou, Z., Zhang, Y., Ren, L. 2014. Influence of pyrolysis temperature on characteristics and heavy metal adsorptive performance of biochar derived from municipal sewage sludge. Bioresour. Technol. 164, 47-54.

[4]Dhyani, V., Bhaskar, T. 2017. A comprehensive review on the pyrolysis of lignocellulosic biomass. Renew. Energy, 129, 695-716.

[5]Girotto, F., Alibardi, L., Cossu, R. 2015. Food waste generation and industrial uses A review. Waste Manage. 45, 32-41.

[6]Godlewska, P., Schmidt, H.P., Ok, Y.S., Oleszczuk, P. 2017. Biochar for composting improvement and contaminants reduction. A review. Bioresour. Technol. 246, 193202.

[7]Hale, S.E., Alling, V., Martinsen, V., Mulder, J., Breedveld, G.D., Cornelissen, G. 2013. The sorption and desorption of phosphate-P, ammonium- $\mathrm{N}$ and nitrate- $\mathrm{N}$ in cacao shell and corn cob biochars. Chemosphere, 91(11), 1612-1619.

[8]Hedstro"m, A. 2001. Ion Exchange of Ammonium in Zeolites A Literature Review. Journal of Environmental Engineering, 127(8), 673-681.

[9]Huang, H., Xiao, X., Yan, B., Yang, L. 2010. Ammonium removal from aqueous solutions by using natural Chinese (Chende) zeolite as adsorbent. J Hazard Mater, 175(1-3), 247-252.

[10]Huda Abdulrazzaq, H.J., Ahmed Husni, and Rosenani Abu-Bakr. 2014. Characterization and stabilisation of biochars obtained from empty fruit bunch, wood, and rice husk. Bioresources, 9(2), 2888-2898.

[11]Jia, M., Wang, F., Bian, Y., Stedtfeld, R.D., Liu, G., Yu, J., Jiang, X. 2018. Sorption of sulfamethazine to biochars as affected by dissolved organic matters of different origin. Bioresour. Technol, 248, 36-43.

[12]Jung, K.W., Kim, K., Jeong, T.U., Ahn, K.H. 2016. Influence of pyrolysis temperature on characteristics and phosphate adsorption capability of biochar derived from wastemarine macroalgae (Undaria pinnatifida roots). Bioresour. Technol, 200, 1024-1028.

[13]Kim, W.K., Shim, T., Kim, Y.S., Hyun, S., Ryu, C., Park, Y.K., Jung, J. 2013. Characterization of cadmium removal from aqueous solution by biochar produced from a giant Miscanthus at different pyrolytic temperatures. Bioresour. Technol, 138, 266-70.

[14]Kizito, S., Wu, S., Kipkemoi Kirui, W., Lei, M., Lu, Q., Bah, H., Dong, R. 2015. Evaluation of slow pyrolyzed wood and rice husks biochar for adsorption of ammonium nitrogen from piggery manure anaerobic digestate slurry. Sci Total Environ, 505, 102-12. 
[15]Komnitsas, K., Zaharaki, D., Pyliotis, I., Vamvuka, D., Bartzas, G. 2015. Assessment of Pistachio Shell Biochar Quality and Its Potential for Adsorption of Heavy Metals. Waste and Biomass Valorization, 6(5), 805-816.

[16]Krevelen, D.v. 1950. Graphical-statistical method for the study of structure and reaction processes of coal. Fuel, 102, 269-284.

[17]Leng, L., Huang, H., Li, H., Li, J., Zhou, W. 2019. Biochar stability assessment methods: A review. Sci Total Environ, 647, 210-222.

[18]Li, M., Liu, Q., Guo, L., Zhang, Y., Lou, Z., Wang, Y., Qian, G. 2013. Cu(II) removal from aqueous solution by Spartina alterniflora derived biochar. Bioresour. Technol. $141,83-88$.

[19]Li, S., Barreto, V., Li, R., Chen, G., Hsieh, Y.P. 2018. Nitrogen retention of biochar derived from different feedstocks at variable pyrolysis temperatures. Journal of Analytical and Applied Pyrolysis, 133, 136-146.

[20]Luo, L., Wang, G., Shi, G., Zhang, M., Zhang, J., He, J., Xiao, Y., Tian, D., Zhang, Y., Deng, S., Zhou, W., Lan, T., Deng, O. 2019. The characterization of biochars derived from rice straw and swine manure, and their potential and risk in $\mathrm{N}$ and $\mathrm{P}$ removal from water. J. Environ. Manage. 245, 1-7.

[21]M. Kithome, J.W.P., L. M. Lavkulich, and A. A. Bomke. 1998. Kinetics of ammonium adsorption and desorption by natural zeolite clinoptilolite. Soil Sci. Soc. of America J. $62(3), 622-629$.

[22]Marco Keiluweit , P.S.N., Mark G. Johnson , and Markus Kleber. 2010. Dynamic molecular structure of plant biomass-derived black carbon. Environmental Sci. \& Technol. 44(4), 1247-1253.

[23]Mukherjee, A., Zimmerman, A.R., Harris, W. 2011. Surface chemistry variations among a series of laboratory-produced biochars. Geoderma, 163(3-4), 247-255.

[24]Park, H.J., Park, Y.-K., Kim, J.S. 2008. Influence of reaction conditions and the char separation system on the production of bio-oil from radiata pine sawdust by fast pyrolysis. Fuel Process. Technol. 89(8), 797-802.

[25]Reguyal, F., Sarmah, A.K. 2018. Site energy distribution analysis and influence of $\mathrm{Fe}_{3} \mathrm{O}_{4}$ nanoparticles on sulfamethoxazole sorption in aqueous solution by magnetic pine sawdust biochar. Environ. Pollut. 233, 510-519.

[26]Shaaban, A., Se, S.-M., Dimin, M.F., Juoi, J.M., Mohd Husin, M.H., Mitan, N.M.M. 2014. Influence of heating temperature and holding time on biochars derived from rubber wood sawdust via slow pyrolysis. J. Analytical and Appl. Pyrolysis, 107, 31-39.

[27]Spokas, K.A., Novak, J.M., Venterea, R.T. 2011. Biochar's role as an alternative Nfertilizer: ammonia capture. Plant and Soil, 350(1-2), 35-42.

[28]Sun, Y., Gao, B., Yao, Y., Fang, J., Zhang, M., Zhou, Y., Chen, H., Yang, L. 2014. Effects of feedstock type, production method, and pyrolysis temperature on biochar and hydrochar properties. Chem. Engineering J. 240, 574-578.

[29]Takaya, C.A., Fletcher, L.A., Singh, S., Anyikude, K.U., Ross, A.B. 2016. Phosphate and ammonium sorption capacity of biochar and hydrochar from different wastes. Chemosphere, 145, 518-527.

[30]Tang, Y., Alam, M.S., Konhauser, K.O., Alessi, D.S., Xu, S., Tian, W., Liu, Y. 2019. Influence of pyrolysis temperature on production of digested sludge biochar and its application for ammonium removal from municipal wastewater. J. of Clean. 
Production, 209, 927-936.

[31]Thines, K.R., Abdullah, E.C., Mubarak, N.M., Ruthiraan, M. 2017. Synthesis of magnetic biochar from agricultural waste biomass to enhancing route for waste water and polymer application: A review. Renewpro and Sustainable Energy Reviews, 67, 257276.

[32]Vassilev, S.V., Baxter, D., Andersen, L.K., Vassileva, C.G. 2010. An overview of the chemical composition of biomass. Fuel, 89(5), 913-933.

[33]Xu, D., Cao, J., Li, Y., Howard, A., Yu, K. 2019. Effect of pyrolysis temperature on characteristics of biochars derived from different feedstocks: A case study on ammonium adsorption capacity. Waste Manag, 87, 652-660.

[34]Y.S. Ho, G.M. 1999. Pseudo-second order model for sorption processes. Process Biochemistry, 34(5), 451-465.

[35]Yan-Hong Jiang, A.-Y.L., Hua Deng, Cheng-Hui Ye, Yu-Qing Wu, Yu-Dan Linmu, HaoLin Hang. 2019. Characteristics of nitrogen and phosphorus adsorption by Mg-loaded biochar from different feedstocks. Bioresour. Technol. 276, 183-189.

[36]Yang, K., Jiang, Y., Yang, J., Lin, D. 2018. Correlations and adsorption mechanisms of aromatic compounds on biochars produced from various biomass at 700 degrees $\mathrm{C}$. Environ. Pollut, 233, 64-70.

[37]Yavari, S., Malakahmad, A., Sapari, N.B., Yavari, S. 2017. Sorption properties optimization of agricultural wastes-derived biochars using response surface methodology. Process Safety and Environmental Protection, 109, 509-519.

[38]Yin, H., Yang, C., Jia, Y., Chen, H., Gu, X. 2018. Dual removal of phosphate and ammonium from high concentrations of aquaculture wastewaters using an efficient two-stage infiltration system. Sci. Total. Environ. 635, 936-946.

[39]Yu, H., Zou, W., Chen, J., Chen, H., Yu, Z., Huang, J., Tang, H., Wei, X., Gao, B. 2018. Biochar amendment improves crop production in problem soils: A review. J Environ. Manage, 232, 8-21.

[40]Yunnen, C., Xiaoyan, L., Changshi, X., Liming, L. 2015. The mechanism of ion exchange and adsorption coexist on medium-low concentration ammonium-nitrogen removal by ion-exchange resin. Environ. Technol. 36(18), 2349-2356.

\section{Figures and Tables}




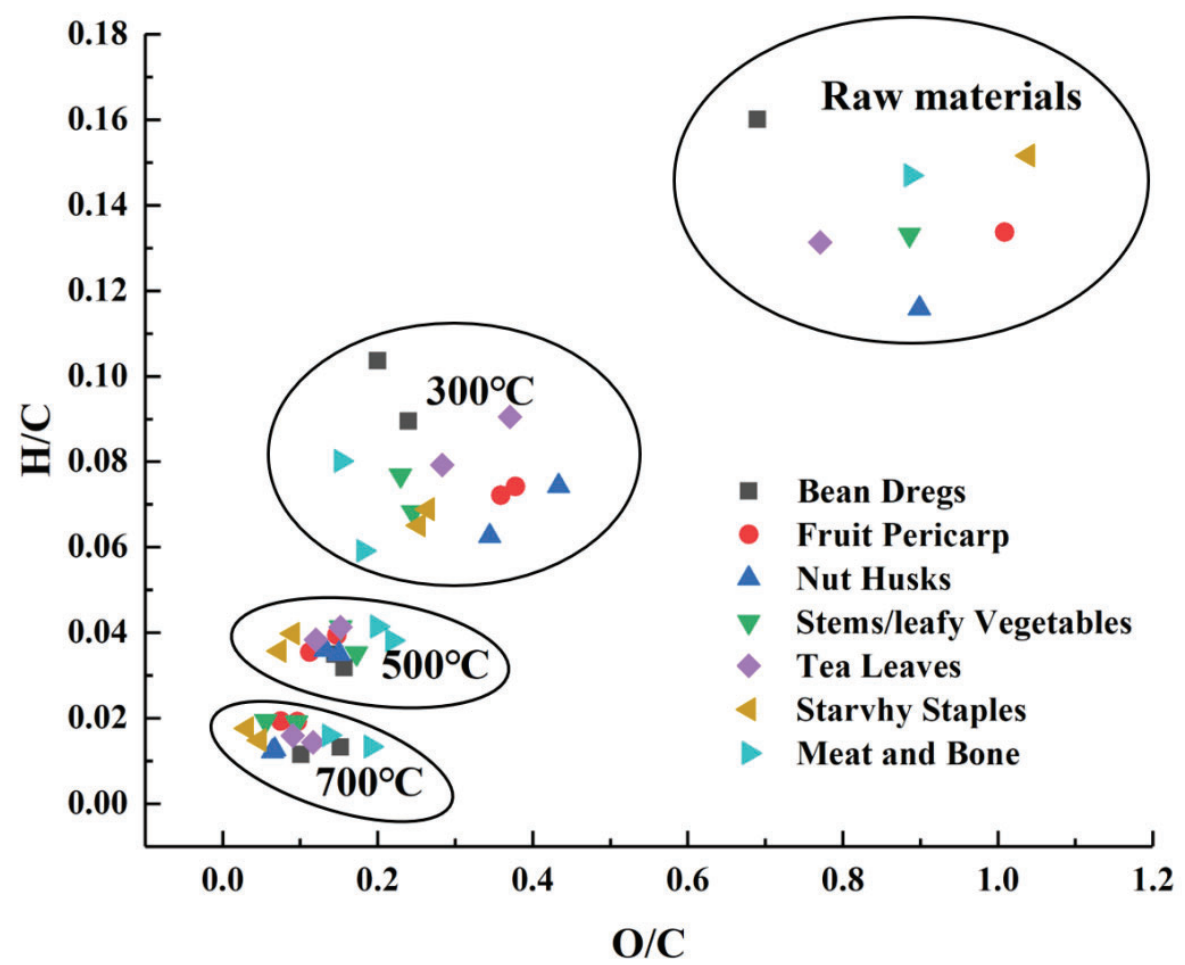

Fig. 1. Van Krevelen diagram for raw materials and biochars produced at pyrolysis temperatures 300,500 and $700^{\circ} \mathrm{C}$ 

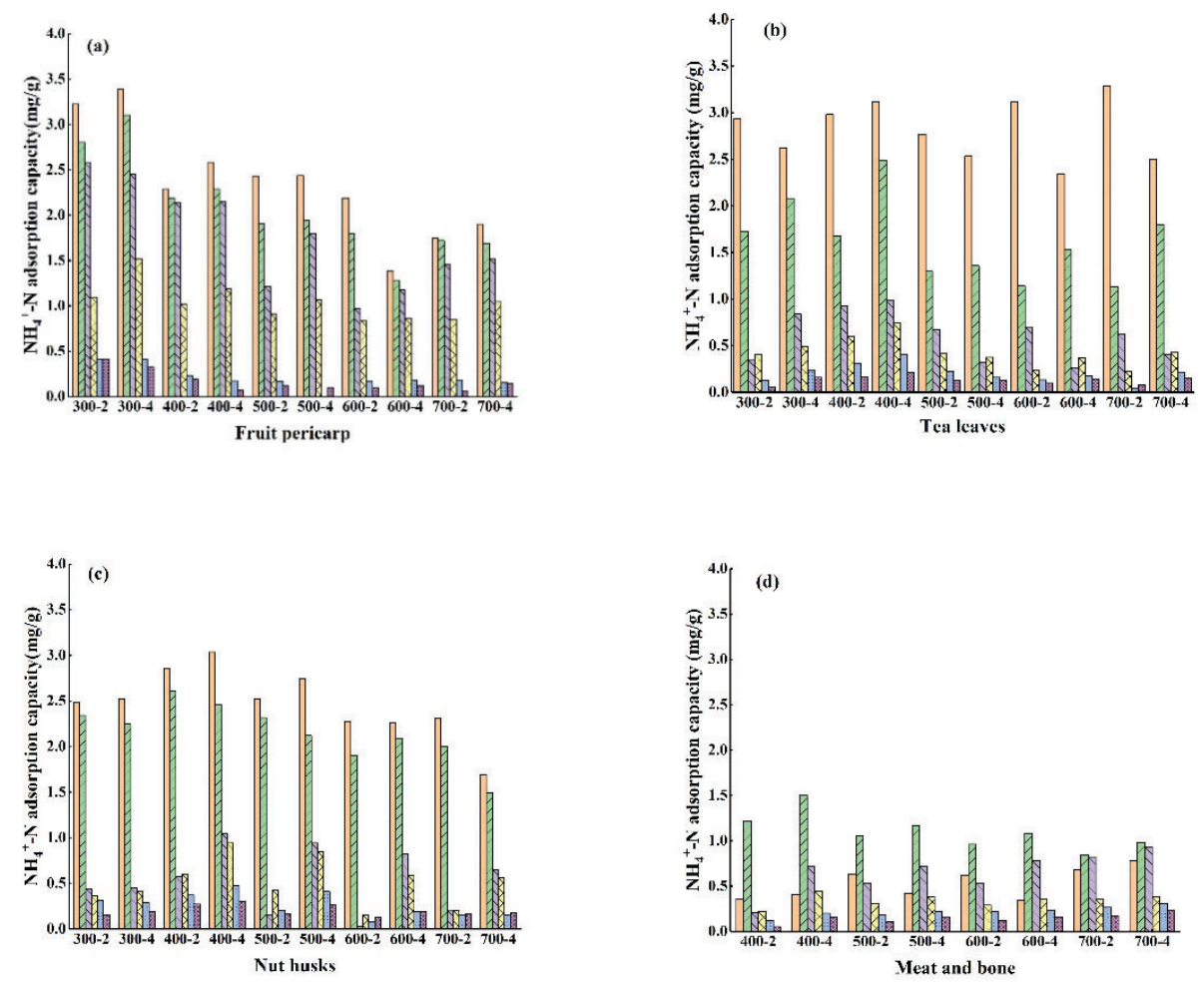

$150 \mathrm{mg} / \mathrm{L} \quad \mathrm{L} \triangle 100 \mathrm{mg} / \mathrm{L} \quad \mathrm{MV} 50 \mathrm{mg} / \mathrm{L} \quad 20 \mathrm{mg} / \mathrm{L} \quad 10 \mathrm{mg} / \mathrm{L} \quad 5 \mathrm{mg} / \mathrm{L}$

Fig. 2. Adsorption capacity of $\mathrm{NH}_{4}{ }^{+}-\mathrm{N}$ of fruit pericarp(a), tea leaves(b), nut husks (c)and meat and bone(d), with the initial biochars concentration ranging from $5 \mathrm{mg} / \mathrm{L}$ to $150 \mathrm{mg} \cdot \mathrm{L}^{-}$
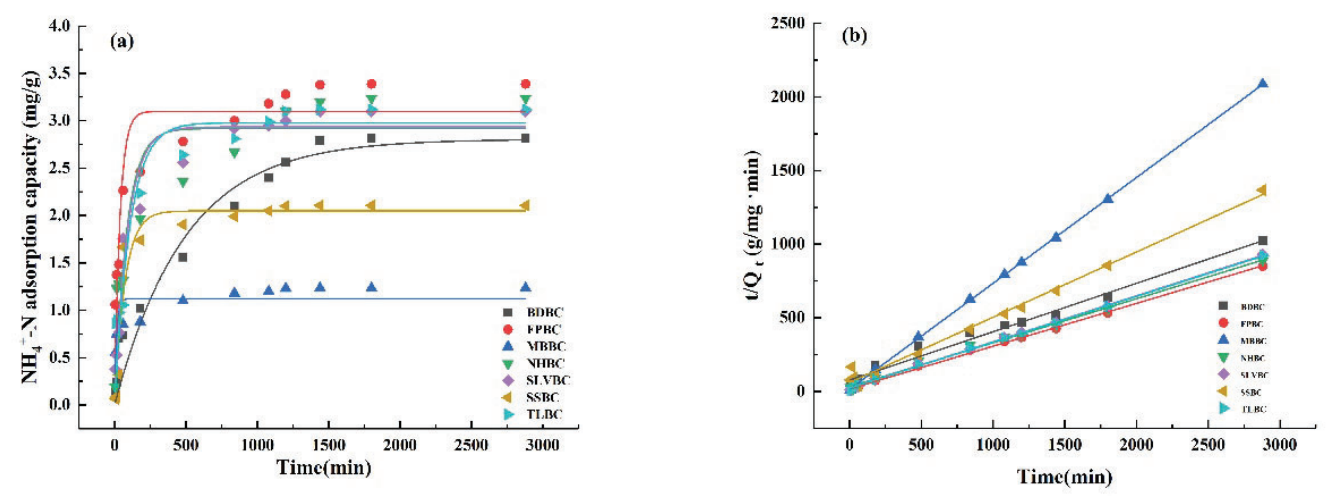
Fig. 3. Adsorption kinetic curves of $\mathrm{NH}_{4}{ }^{+}-\mathrm{N}$ on the 7 different food waste biochars.

(a) Food waste biochar residence time for 4 hours fitting the pseudo-first order model

(b) Food waste biochar residence time for 4 hours fitting the pseudo-second order model
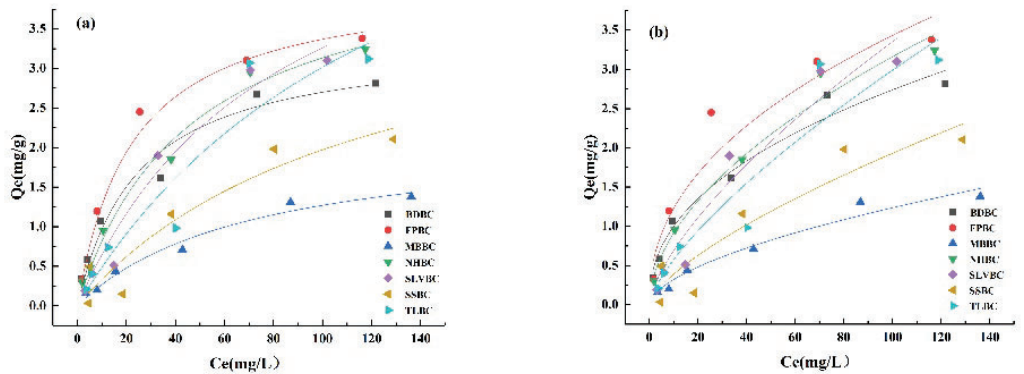

Fig. 4. Adsorption isotherms of $\mathrm{NH}_{4}{ }^{+}-\mathrm{N}$ for the 7 different food waste biochars.

(a) Food waste biochar residence time for 4 hours fitting the Langmuir model

(b) Food waste biochar residence time for 4 hours fitting the Freundlich model 

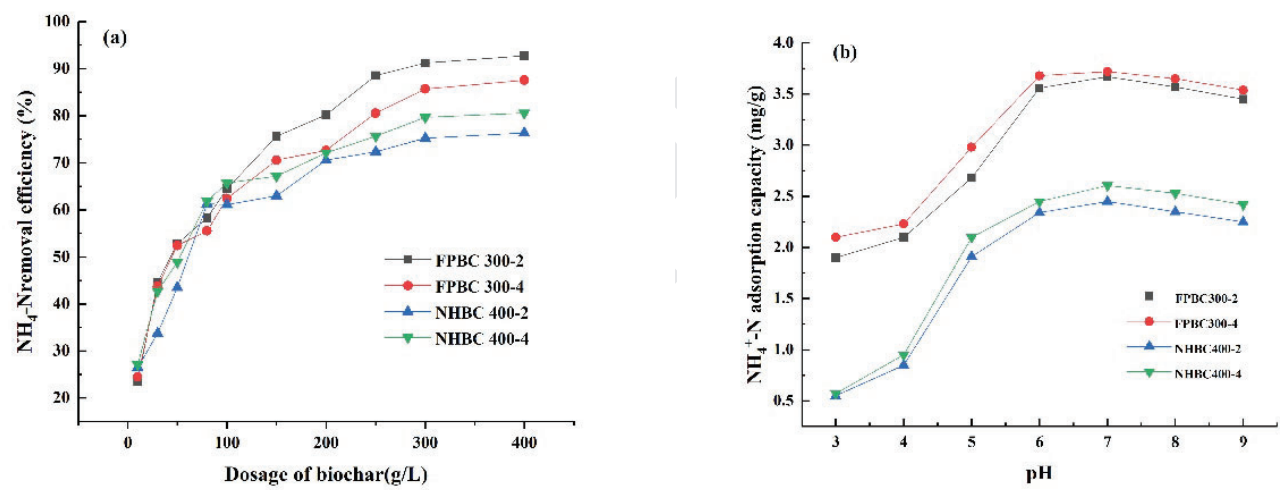

Fig. 5. (a) Effect of biochar dosage on $\mathrm{NH}_{4}{ }^{+}-\mathrm{N}$ adsorption (b) Effect of $\mathrm{pH}$ on $\mathrm{NH}_{4}{ }^{+}-\mathrm{N}$ adsorption 

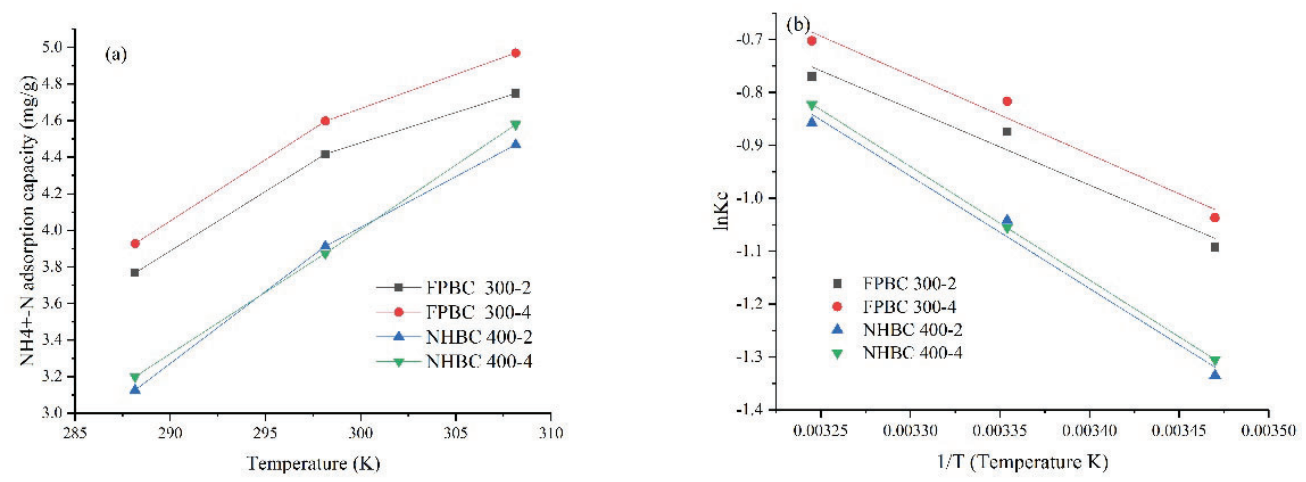

Fig. 6. (a) Effect of temperature on $\mathrm{NH}_{4}{ }^{+}-\mathrm{N}$ adsorption (b) Thermodynamics of $\mathrm{NH}_{4}{ }^{+}-\mathrm{N}$ onto biochar 


\section{Table 1}

Ultimate analysis and proximate analysis of raw materials

\begin{tabular}{|c|c|c|c|c|c|c|c|c|c|c|c|c|}
\hline \multirow[b]{2}{*}{ sample } & \multicolumn{4}{|c|}{ Ultimate analysis } & \multicolumn{3}{|c|}{ Atomic ratios } & \multicolumn{3}{|c|}{ Proximate analysis } & \multirow[b]{2}{*}{ Zeta } & \multirow[b]{2}{*}{$\mathrm{pH}$} \\
\hline & $\begin{array}{l}\mathrm{C} \\
(\%)\end{array}$ & $\begin{array}{c}\mathrm{H} \\
(\%)\end{array}$ & $\begin{array}{c}\mathrm{O} \\
(\%)\end{array}$ & $\begin{array}{l}\mathrm{N} \\
(\%)\end{array}$ & $\mathrm{H} / \mathrm{C}$ & $\mathrm{O} / \mathrm{C}$ & $(\mathrm{O}+\mathrm{N}) / \mathrm{C}$ & $\begin{array}{l}\text { Ash } \\
(\%)\end{array}$ & $\begin{array}{c}\text { Volatile } \\
\text { content (\%) }\end{array}$ & $\begin{array}{c}\text { Fixed } \\
\text { carbon(\%) }\end{array}$ & & \\
\hline Bean dreg & 49.34 & 7.9 & 34.04 & 4.54 & 0.16 & 0.69 & 0.78 & 4.17 & 80.025 & 15.805 & -13.5 & 5.97 \\
\hline \multicolumn{13}{|l|}{ Fruit } \\
\hline pericarp & 45.26 & 6.05 & 45.65 & 0.31 & 0.13 & 1.01 & 1.02 & 2.81 & 73.855 & 23.335 & -16.65 & 4.76 \\
\hline Nut husk & 47.74 & 5.53 & 42.91 & 0.31 & 0.12 & 0.90 & 0.91 & 3.75 & 71.28 & 24.97 & -5.3 & 5.33 \\
\hline \multicolumn{13}{|l|}{ Stems } \\
\hline leafy & 42.07 & 5.6 & 37.28 & 3.51 & 0.13 & 0.89 & 0.97 & 11.46 & 68.325 & 20.215 & -4.01 & 5.11 \\
\hline \multicolumn{13}{|l|}{ vegetables } \\
\hline Tea leaves & 49.35 & 6.48 & 38.04 & 3.32 & 0.13 & 0.77 & 0.84 & 2.82 & 72.265 & 24.915 & -28.4 & 6.07 \\
\hline Starchy & 44.65 & 6.77 & 46.39 & 1.74 & 0.15 & 1.04 & 1.08 & 0.45 & 79.665 & 19.885 & -16.96 & 6.19 \\
\hline
\end{tabular}




\section{staples}

Meat and

$\begin{array}{lllllllll}37.08 & 5.45 & 32.92 & 5.73 & 0.15 & 0.89 & 1.04 & 18.8 & 70.465\end{array}$

10.735

$-14.93 \quad 6.37$ 


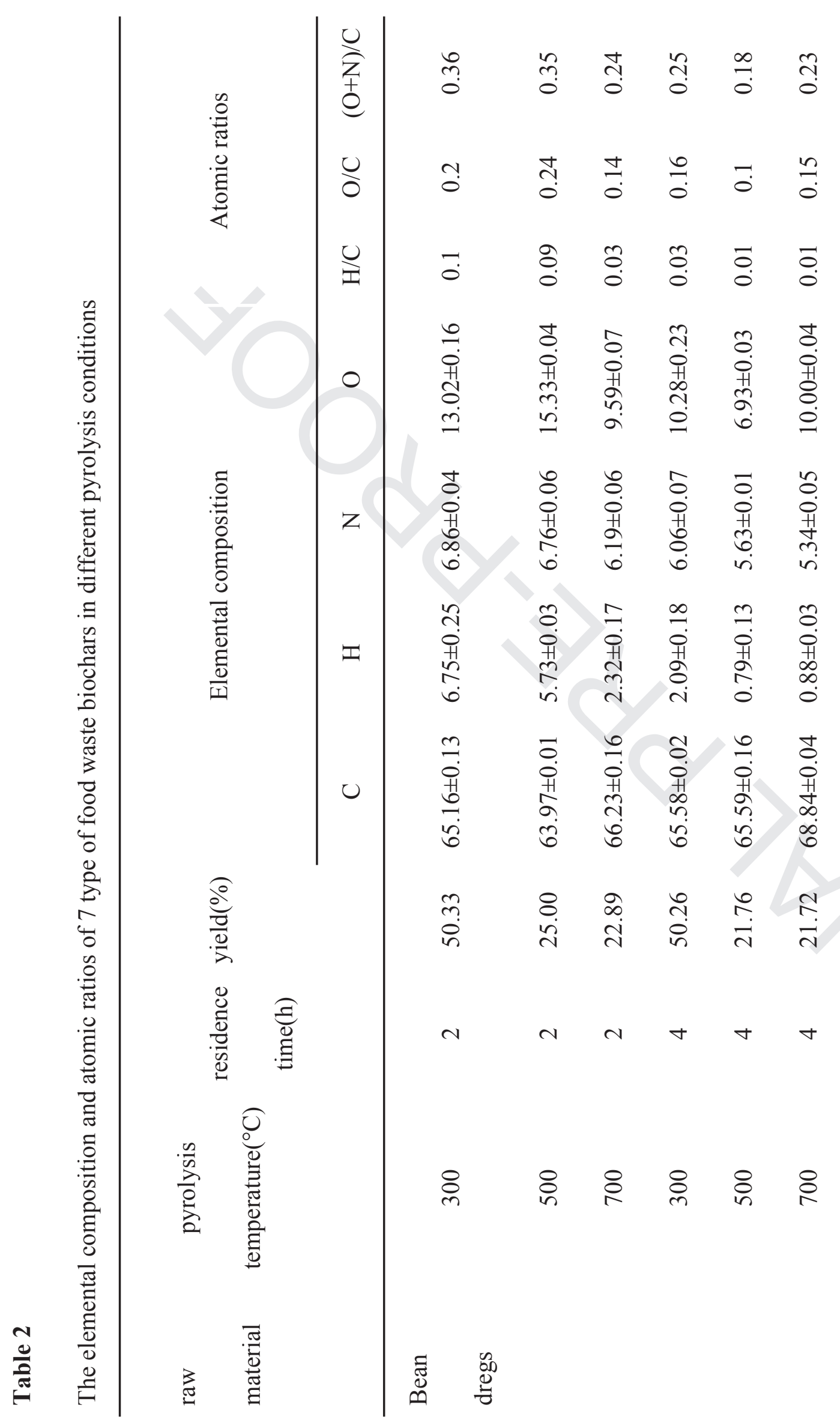




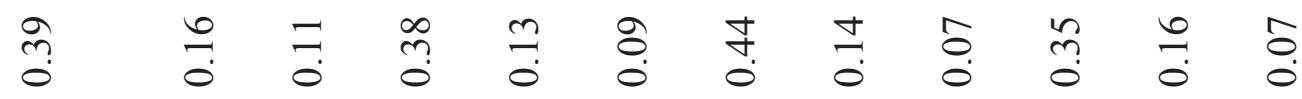

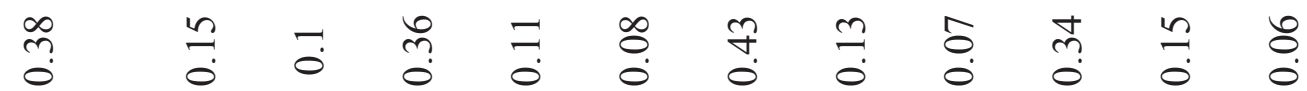

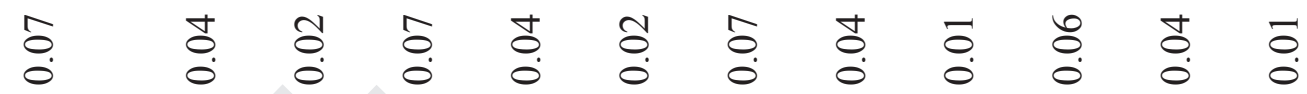

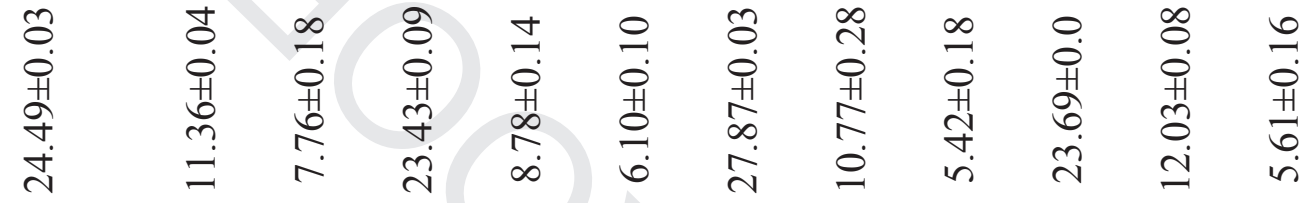

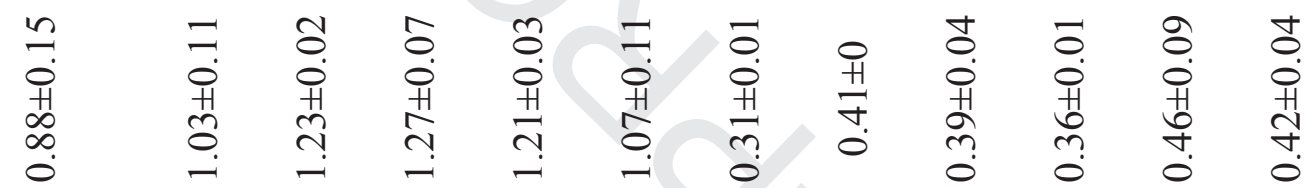

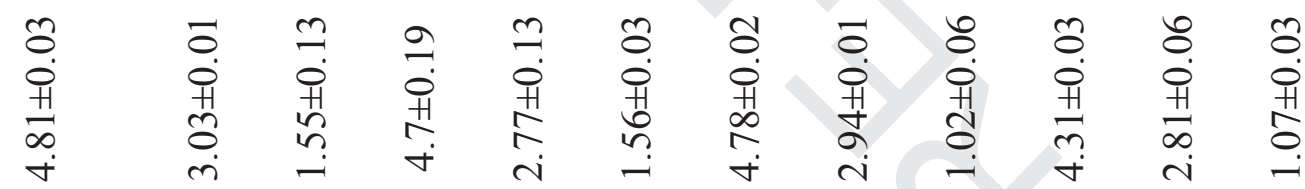

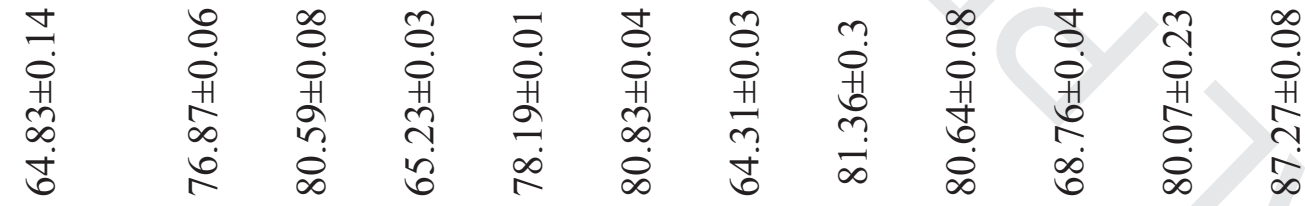

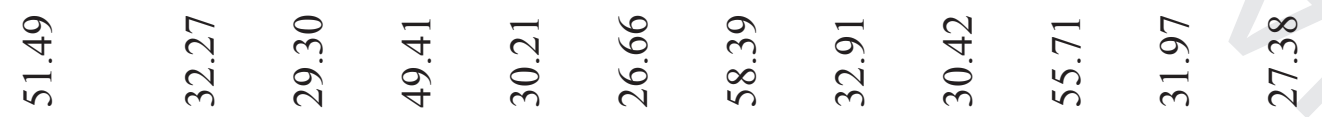

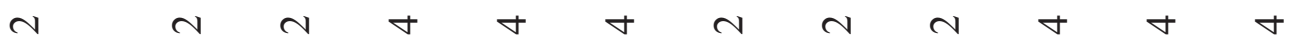

\&

党 


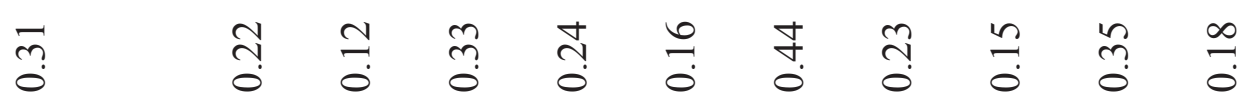

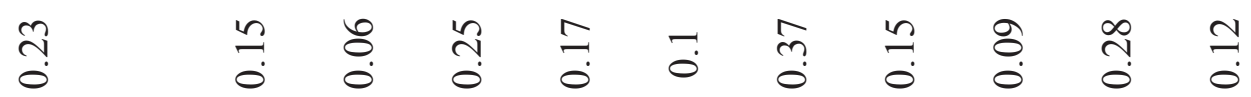

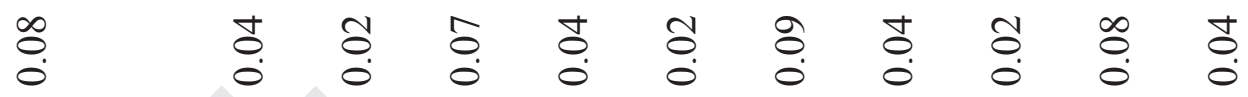

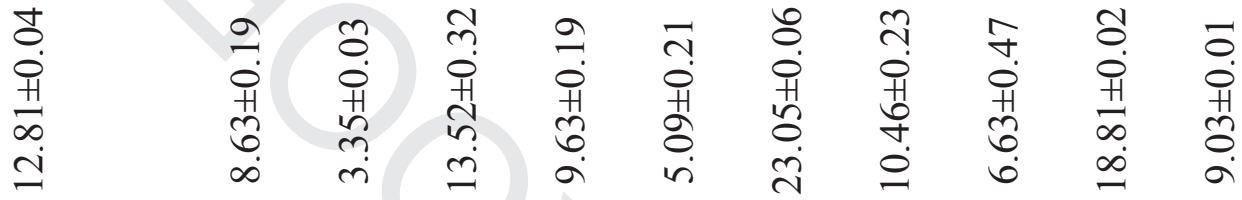

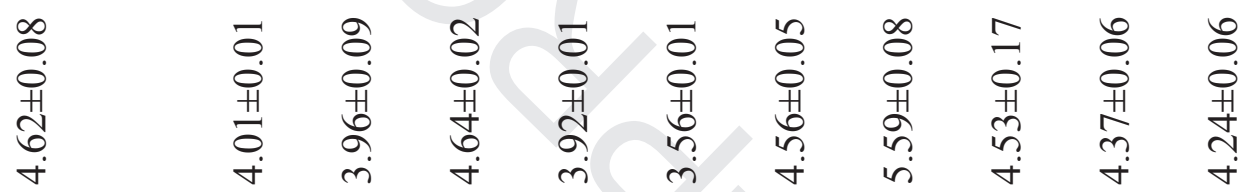

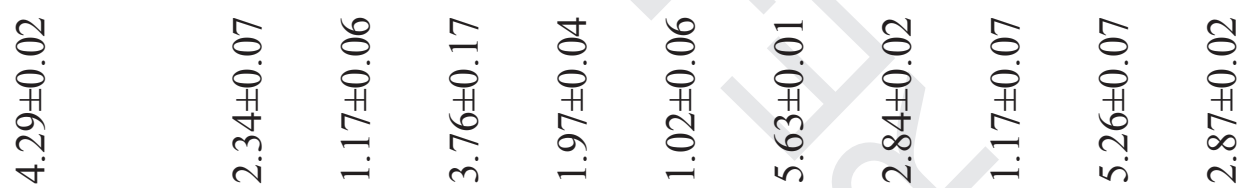

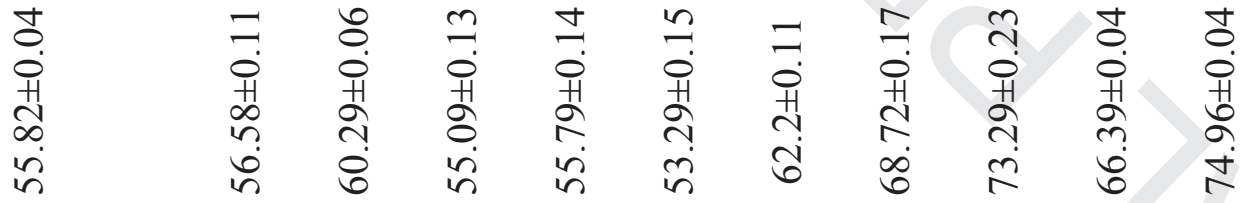

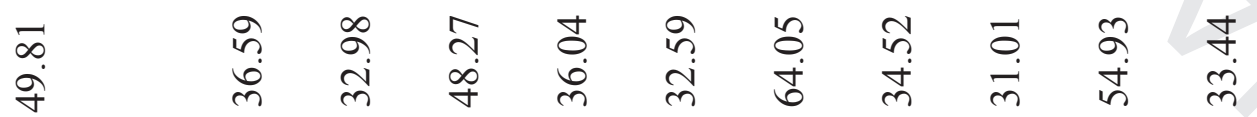

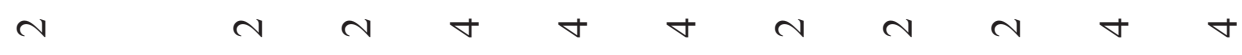

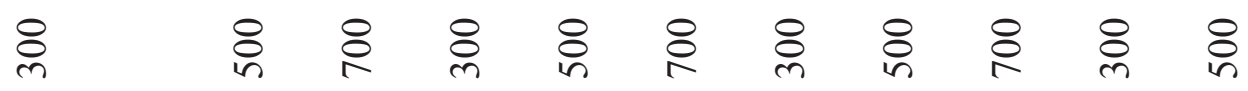

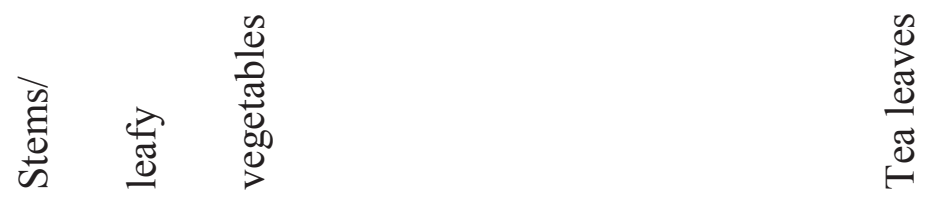




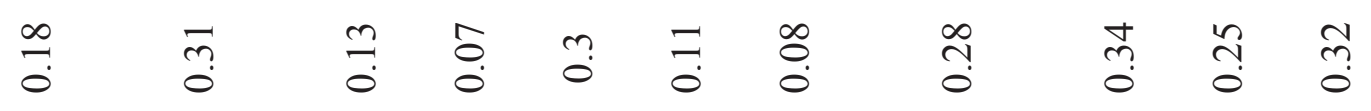

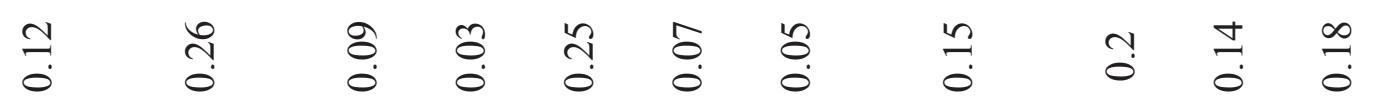

형

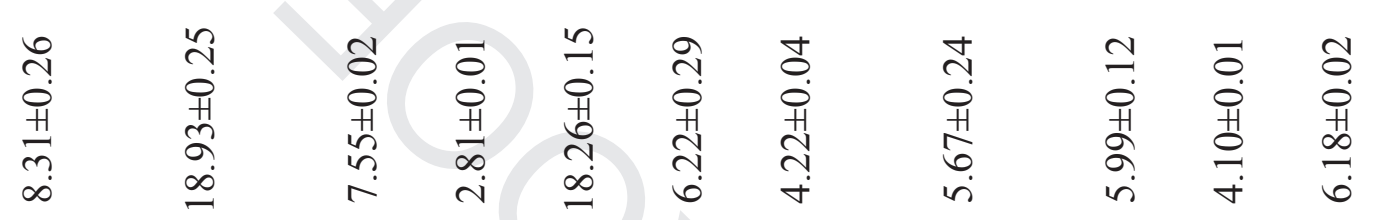

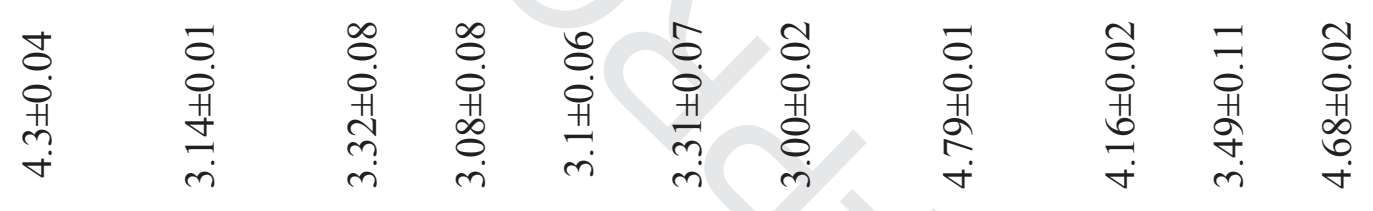

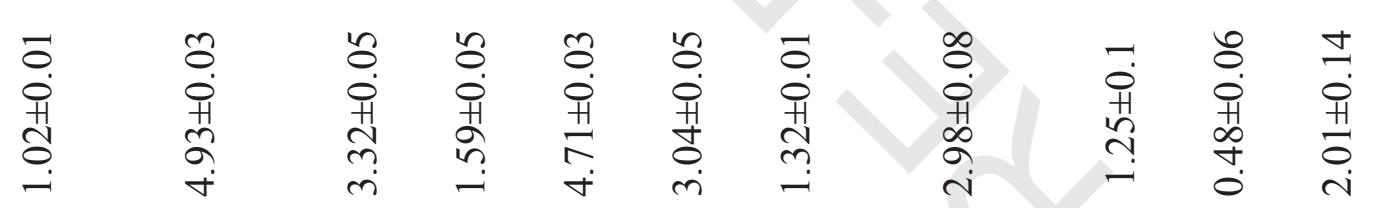

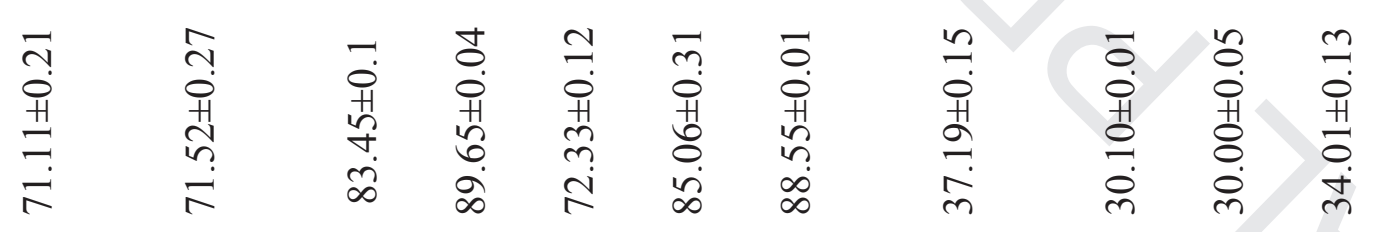

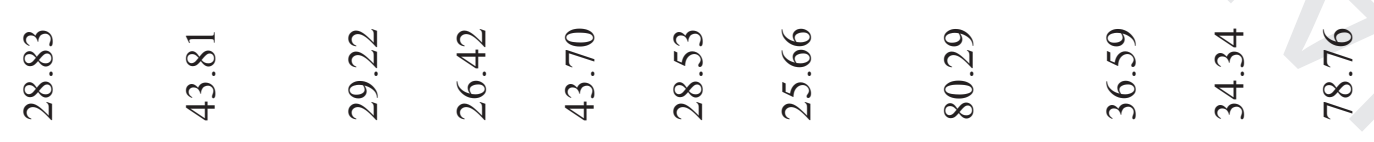

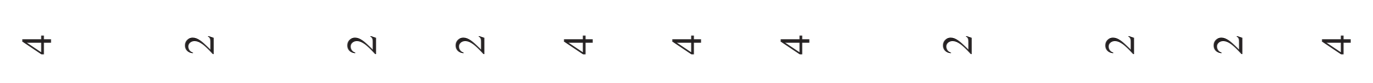

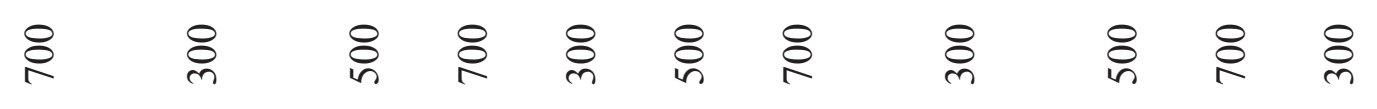

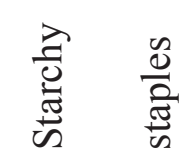

喜量高 


$$
\begin{aligned}
& \stackrel{n}{0} \\
& \text { กิ } \\
& \begin{array}{ll}
\hline & 0 \\
0 & 0
\end{array}
\end{aligned}
$$

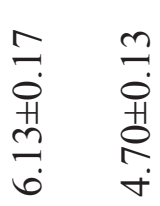

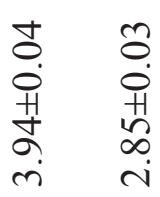

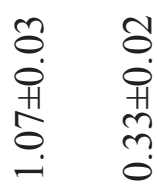

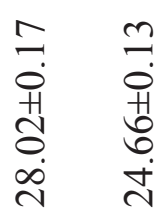

$$
\begin{aligned}
& \begin{array}{ll}
\stackrel{0}{n} & \dot{+} \\
\text { m }
\end{array} \\
& \checkmark \quad \forall \\
& \text { 유융 }
\end{aligned}
$$


Table 3

The characteristics of the food waste-based biochar

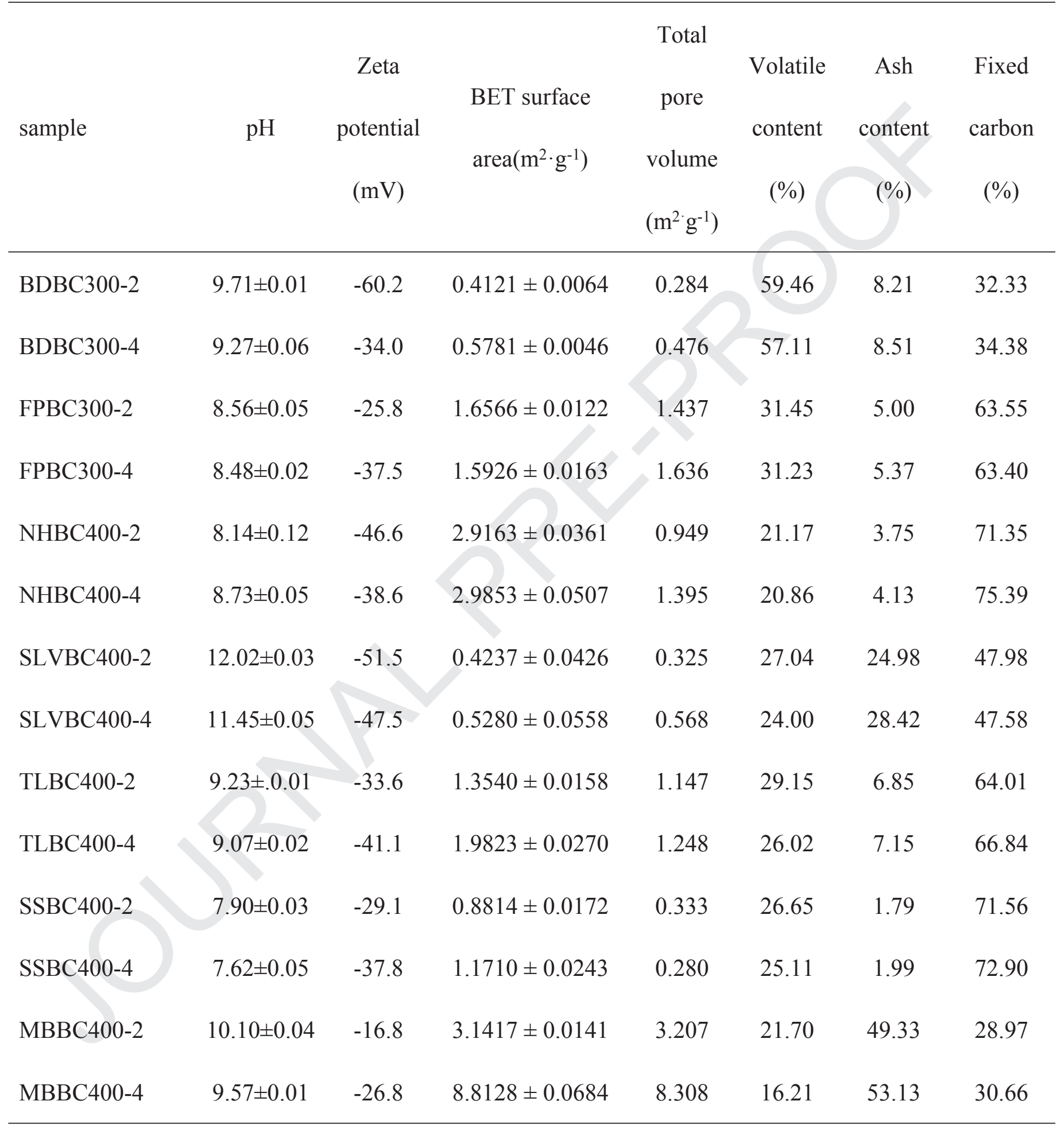

Table 4

Adsorption kinetics parameters for the 7 types of food waste biochar. 


\begin{tabular}{|c|c|c|c|c|c|c|}
\hline \multirow[b]{2}{*}{ Sample } & \multicolumn{3}{|c|}{ Pseudo first order } & \multicolumn{3}{|c|}{ Pseudo second order } \\
\hline & $\begin{array}{c}\text { Q e }(\mathrm{mg} \cdot \mathrm{g} \\
-1)\end{array}$ & $\begin{array}{c}\mathrm{K}_{1}(\min \\
-1)\end{array}$ & $\mathrm{R}^{2}$ & $\begin{array}{c}\mathrm{Q} \text { e }(\mathrm{mg} \cdot \mathrm{g} \\
-1)\end{array}$ & $\begin{array}{c}\mathrm{K}_{2}\left(\mathrm{q} \cdot \mathrm{mg}^{-1} \cdot \mathrm{min}^{-}\right. \\
\left.{ }^{1}\right)\end{array}$ & $\mathrm{R}^{2}$ \\
\hline BDBC300-4 & 2.8056 & 0.0020 & $\begin{array}{c}0.947 \\
0\end{array}$ & 3.0393 & 0.0132 & $\begin{array}{c}0.993 \\
6\end{array}$ \\
\hline FPBC300-4 & 3.0992 & 0.0266 & $\begin{array}{c}0.822 \\
2\end{array}$ & 3.4368 & 0.0635 & $\begin{array}{c}0.998 \\
3\end{array}$ \\
\hline MBBC400-4 & 1.2896 & 0.0646 & $\begin{array}{c}0.608 \\
0\end{array}$ & 1.3910 & 0.0677 & $\begin{array}{c}0.999 \\
8\end{array}$ \\
\hline NHBC400-4 & 2.9181 & 0.0116 & $\begin{array}{c}0.841 \\
4\end{array}$ & 3.3436 & 0.0323 & $\begin{array}{c}0.995 \\
8\end{array}$ \\
\hline SLVBC400-4 & 2.9358 & 0.0108 & $\begin{array}{c}0.952 \\
0\end{array}$ & 3.1958 & 0.0421 & $\begin{array}{c}0.992 \\
0\end{array}$ \\
\hline SSBC400-4 & 2.0486 & 0.0137 & $\begin{array}{c}0.928 \\
0\end{array}$ & 2.2545 & 0.0167 & $\begin{array}{c}0.990 \\
4\end{array}$ \\
\hline TLBC400-4 & 2.9783 & 0.0094 & $\begin{array}{c}0.895 \\
0\end{array}$ & 3.2100 & 0.0456 & $\begin{array}{c}0.998 \\
5\end{array}$ \\
\hline
\end{tabular}


Table 5

Temperature

Sample $\mathrm{Kc} \quad \Delta \mathrm{G}\left(\mathrm{kJ} \cdot \mathrm{mol}^{-1}\right) \quad \Delta \mathrm{H}\left(\mathrm{kJ} \cdot \mathrm{mol}^{-1}\right) \quad \Delta \mathrm{S}\left(\mathrm{J} \cdot \mathrm{mol} \mathrm{K}^{-1}\right) \quad \mathrm{R}^{2}$

(K)

\begin{tabular}{lllllll}
\hline FPBC $300-2$ & 288.15 & 0.335 & 2.578 & 11.968 & 32.589 & 96.640 \\
\hline
\end{tabular}

Langmuir and Freundlich parameters for $\mathrm{NH}_{4}{ }^{+}-\mathrm{N}$ adsorption on 7 different food waste biochars

\begin{tabular}{lcccccc}
\hline \multirow{2}{*}{ sample } & \multicolumn{3}{c}{ Langmuir model } & \multicolumn{3}{c}{ Freundlich model } \\
\cline { 2 - 7 } & $\mathrm{K}_{\mathrm{L}}\left(\mathrm{L} \cdot \mathrm{mg}^{-1}\right)$ & $\mathrm{Q}_{\max }\left(\mathrm{mg} \cdot \mathrm{g}^{-1}\right)$ & $\mathrm{R}^{2}$ & $\mathrm{~K}_{\mathrm{F}}\left(\mathrm{mg} \cdot \mathrm{g}^{-1}\right)$ & $1 / \mathrm{n}$ & $\mathrm{R}^{2}$ \\
\hline BDBC300-4 & 0.0403 & 3.3686 & 0.9775 & 0.4395 & 0.3618 & 0.9634 \\
FPBC300-4 & 0.4444 & 4.1267 & 0.9682 & 0.4469 & 0.4381 & 0.9066 \\
MBBC400-4 & 0.0141 & 2.1745 & 0.9774 & 0.5868 & 0.0828 & 0.9662 \\
NHBC400-4 & 0.0217 & 4.5776 & 0.9862 & 0.5413 & 0.2612 & 0.9763 \\
SLVBC400-4 & 0.0122 & 5.9278 & 0.9671 & 0.6877 & 0.1412 & 0.9298 \\
SSBC400-4 & 0.0084 & 4.3122 & 0.9047 & 0.6984 & 0.0773 & 0.8849 \\
TLBC400-4 & 0.0072 & 7.174 & 0.9077 & 0.7187 & 0.1092 & 0.8896 \\
\hline
\end{tabular}

\section{Table 6}

Thermodynamic parameters for ammonia nitrogen adsorption from aqueous solution onto FPBC and BDBC at $150 \mathrm{mg} / \mathrm{L}$ 